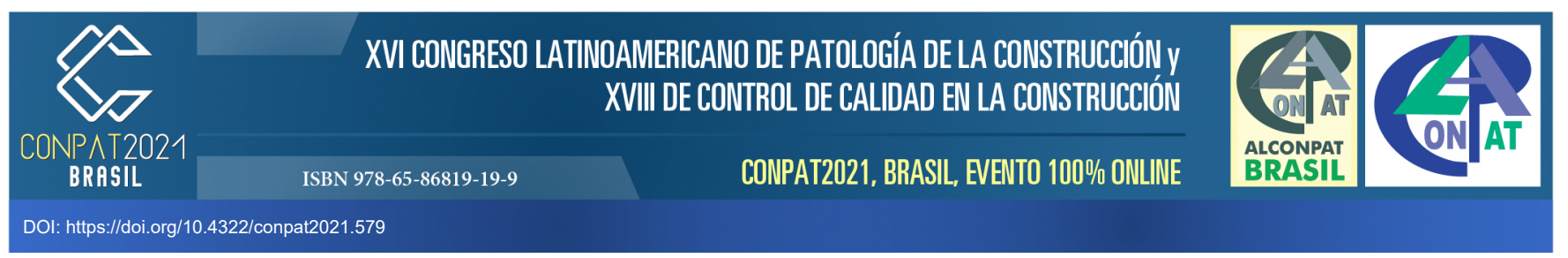

\title{
PATOLOGIA DE EDIFICAÇÕES NO ESTADO DO PARÁ
}

\author{
S. RAIOL ${ }^{1 *}$, D. OLIVEIRA ${ }^{2}$, P. HELENE ${ }^{3}$ \\ *Autor de contato: socorroraiolb22@gmail.com
${ }^{1}$ Instituto de Criminalística, Centro de Perícias Científicas "Renato Chaves", Pará, Brasil
${ }^{2}$ Universidade Federal do Pará, Pará, Brasil
${ }^{1}$ Universidade de São Paulo USP, PHD Engenharia, São Paulo, Brasil

\begin{abstract}
RESUMO
Este estudo é sobre as manifestações patológicas em edificações no Estado do Pará, suas origens, agentes causadores, mecanismos de ocorrências e consequências, e conforme a sua extensão, as manifestações patológicas podem levar a edificação ao colapso. Para tanto foi realizada a análise que correspondeu ao registro de 2879 ocorrências de problemas patológicos, que foram objeto de perícias do Centro de Perícias Científicas "Renato Chaves" do Estado do Pará, entre os anos de 2011 a 2018 e filtrados para 514, os quais atenderam ao tema desta pesquisa, e culminou na demonstração das origens das manifestações patológicas, através de gráficos, inclusive através do método de demonstração e combinação de dados, utilizando o método de georreferenciamento de dados. E para exemplificar são apresentados dois casos periciais de edificações colapsadas.
\end{abstract}

\section{Palavras-Chaves}

Construção civil; patologia das construções; estruturas de concreto.

\section{BUILDINGS' PATHOLOGY IN PARÁ STATE}

\begin{abstract}
This study is about the pathological manifestations in buildings in the State of Pará, their origins, causative agents, mechanisms of occurrences and consequences, and according to their extension, the pathological manifestations can cause the building to collapse. To this end, the analysis was carried out, which corresponded to the record of 2879 occurrences of pathological problems, which were the subject of expertise from the Center of Scientific Expertise "Renato Chaves" of the State of Pará, between the years 2011 to 2018 and filtered to 514, which met the theme of this research, and culminated in the demonstration of the origins of pathological manifestations, through graphics, including through the method of demonstration and combination of data, using the method of georeferencing data. For example, two expert cases of collapsed buildings are presented.
\end{abstract}

\section{Key words}

Construction; building pathology; concrete estructures.

\section{INTRODUÇÃO}

As construções de modo geral, seja um imóvel, obras de arte especiais e outros, desde sua concepção até a entrega da edificação, necessitam de cuidados técnicos para poderem atender ao 
seu objetivo durante sua vida útil, contemplando a durabilidade, desempenho e funcionalidade e atender às necessidades do ser humano como um todo. Entretanto as edificações, com o passar do tempo, vão envelhecendo e, dependendo do ambiente em que estão construídas, vão apresentando problemas crescentes de degradação, comprometendo a sua funcionalidade e estabilidade, Mehta e Monteiro (1994).

Essas doenças podem ser invisíveis ou apresentarem-se como manifestações patológicas que podem ocorrer em qualquer fase da vida da edificação. Após a conclusão da edificação alguns desses problemas patológicos podem ser evitadas ou minorados através de manutenção preventiva, e quando forem diagnosticadas, seja na sua supra estrutura como na sua infraestrutura, precisarão de uma terapia, uma adoção de medidas para restabelecer a integridade da edificação, visando o bem estar de seus usuários.

A partir de então surgiu uma ciência para análise desse problema, chamada patologia das construções, que é uma ciência que estuda os sintomas, os mecanismos, os agentes causadores da ocorrência de determinada manifestação patológica, Souza e Ripper (1998).

De acordo com Helene et al. (2011), uma manifestação patológica é a expressão resultante de um mecanismo de degradação e a patologia é uma ciência formada por um conjunto de teorias que serve para explicar o mecanismo e a causa da ocorrência de determinada manifestação patológica. Em função disso, fica claro que a patologia é um termo muito mais amplo do que manifestação patológica, uma vez que ela é a ciência que estuda e tenta explicar a ocorrência de tudo o que se relaciona com a degradação de uma edificação.

Diante das considerações abordadas, um dos pontos que chama a atenção é que para reduzir o número de edificações que apresentem muitos problemas patológicos, estas deverão ser submetidas a um programa de manutenção periódica, além de contarem com um projeto e construção em conformidade com as normas técnicas vigentes.

Segundo Cunha et al. (1996), as normas brasileiras de projeto de estruturas em concreto, mais especificamente a NBR 6118 (ABNT, 2014), preconizam verificações nos níveis dos estados limites de serviço e estados limites últimos. Portanto, para a análise do colapso de uma estrutura de concreto armado, é indispensável a verificação da estabilidade global da estrutura, referente aos esforços solicitantes através dos carregamentos impostos na estrutura, bem como os deslocamentos e as deformações decorrentes dos efeitos de $2^{\mathrm{a}}$ ordem, sofridos pela estrutura, afim de determinar se a estrutura executada, atendia ao Estado Limite de Serviço (ELS) e Estado Limite Último (ELU), conforme o que prevê as recomendações do item 10 (Segurança e estados limites) da ABNT NBR 6118.

E para tanto, considerando a complexidade para se identificar de imediato as origens e os agentes causadores, que levam uma edificação ao colapso, Raiol e Maciel (2013) propuseram um roteiro com métodos utilizados, para elucidação das causas de um acidente estrutural em edificações de concreto armado, o qual é submetido ao que preconiza as normas técnicas específicas, referentes a todos os fatores peculiares ao sinistro, e contemplam várias etapas exibidas conforme proposto no fluxograma da Figura 1. 


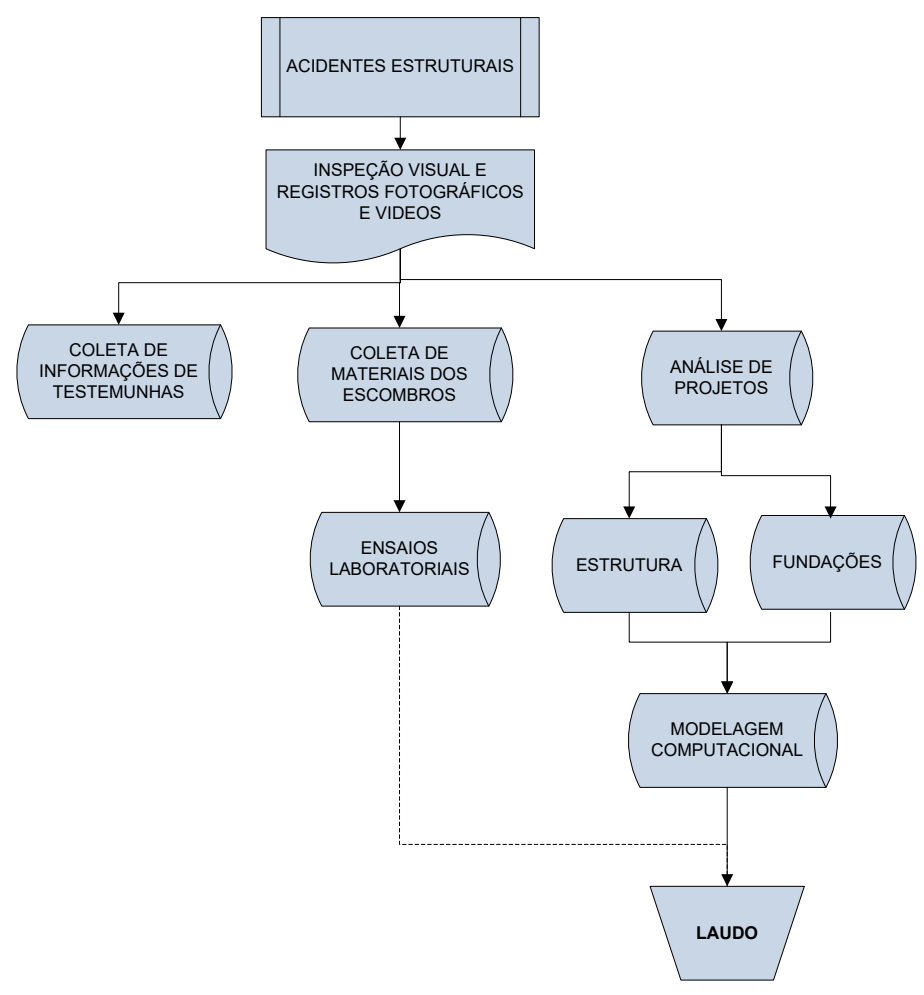

Figura 1: Fluxograma de metodologia para avaliação de acidentes estruturais

\section{ACIDENTES NO ESTADO DO PARÁ}

No estado do Pará, assim como em outros estados do Brasil e no mundo, a engenharia civil vem sofrendo com falhas, erros e escolhas equivocadas, que podem, inclusive, causar desabamentos, como os já ocorridos nas últimas décadas, conforme, por exemplo, o mostrado na Figura 2.

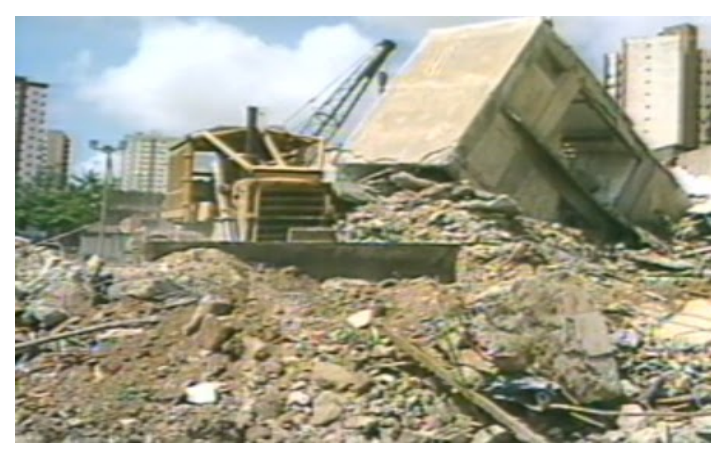

Figura 2. Desabamento do edifício Raimundo Farias ocorrido em 1987, que apresentava 13 andares, e estava em fase de execução. 39 operários vieram a óbito. Belém/ $\mathrm{Pa}$.

Por conta de acidentes como o relatado na Fig. 2, foi constituído o Centro de Perícias Científicas "Renato Chaves" que começou a realizar perícias em edificações em 1990, através do Instituto de Criminalística, setor de Engenharia Legal, que atendeu vários casos importantes entre eles os dois relatados a seguir.

Em 2008 ocorreu o desabamento do reservatório elevado (Figura 3a, 3b e 3c) ocorrido em 2008, situado no município de Marabá, com capacidade para 2.000.000 litros, vitimando fatalmente dois operários. Formato cilíndrico composto de anel externo de $8,25 \mathrm{~m}$ de diâmetro e $0,25 \mathrm{~m}$ de 
espessura e anel interno de $1,45 \mathrm{~m}$ de diâmetro e espessura de $0,25 \mathrm{~m}$ e altura total de $57,10 \mathrm{~m}$, dividida em seis células.

O diagnóstico indicou que o desabamento ocorreu em virtude do rompimento das lajes intermediárias, no trecho do apoio do pilar central, e do esmagamento da base do pilar externo (anel), no trecho de apoio nas cintas radiais, devido à ausência de armadura de punção nas lajes intermediárias, conforme Laudo de Exame $n^{0}$ 103/2008, Livro 1216, F. 204 a 220 do Instituto de Criminalística.

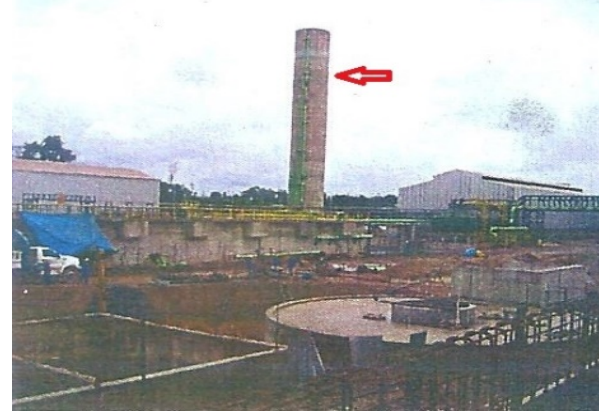

(a)

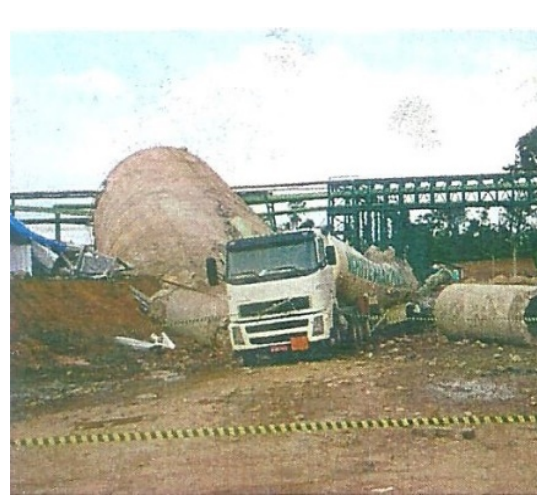

(b)

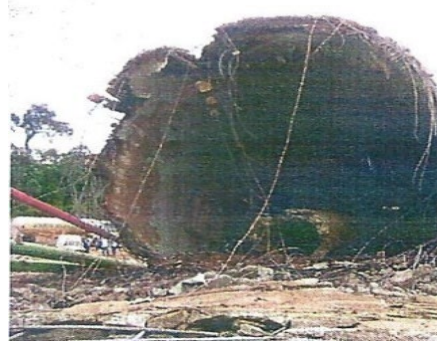

(c)

Figura 3. a) Vista geral da área da siderúrgica antes do acidente; b) Vista geral do colapso; c)

Vista da base do reservatório.

Relata-se também o colapso de um edifício em Belém, ocorrido em 2011. As figuras 4a, 4b, 4c, 4d e 4e, mostram o edifício que desabou em Belém em 2011, vitimando três pessoas, sendo dois operários e a moradora da casa adjacente. O Laudo de Exame no 124/2011, Livro 010/ENG descreve o diagnóstico que apontou erro no sistema estrutural proposto no projeto estrutural, não consideração da ação do vento e não satisfazia a condição necessária de um modelo capaz de garantir a estabilidade global do edifício de trinta e quatro pavimentos, distribuídos em quatro áreas de uso comum, como subsolo, térreo, $1^{\circ}$ nível e $2^{\circ}$ nível e trinta pavimentos tipo e uma cobertura, totalizando uma altura de 104,7 m. O edifício se encontrava em fase de acabamento e possuía o concreto especificado com uma resistência de $35 \mathrm{MPa}$ para a superestrutura e $20 \mathrm{MPa}$ para as fundações. 


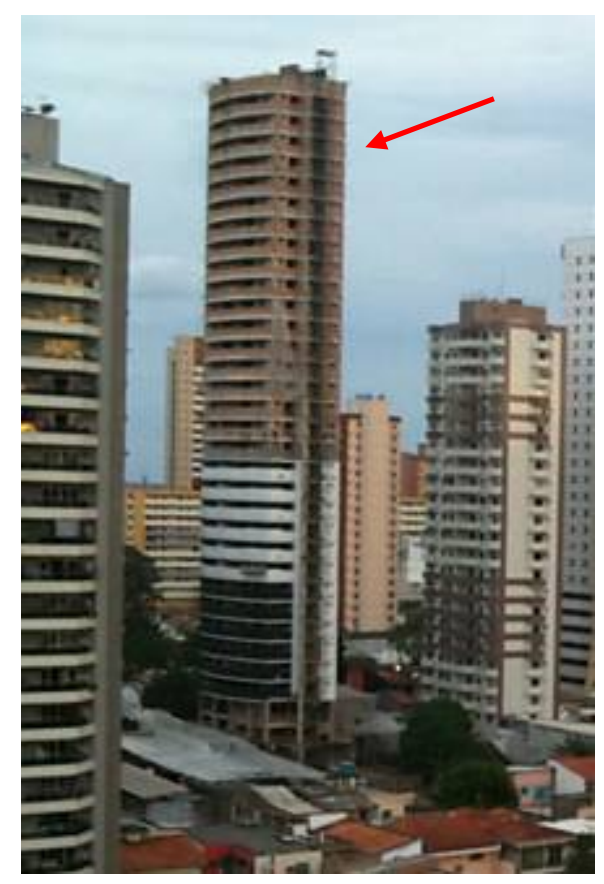

(a)

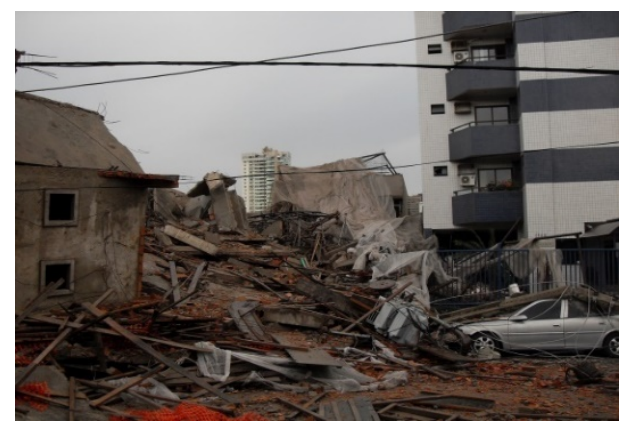

(b)

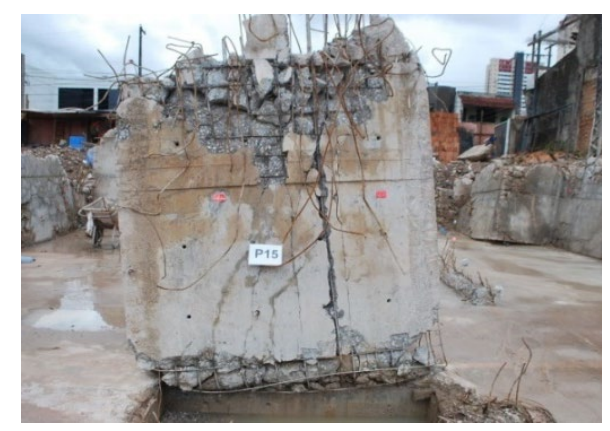

(d)

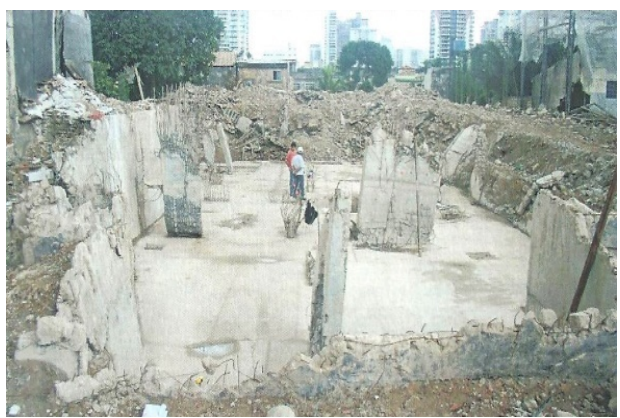

(c)

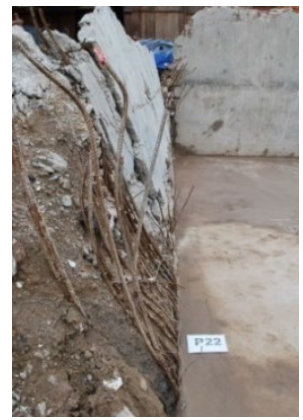

(e)

Figura 4. a) Vista do edifício (seta) pouco antes de colapsar; b), c), d) e e) escombros do edifício após o seu desabamento.

Por conta desses vários exemplos, neste artigo propõem-se, uma metodologia para análise global de problemas patológicos. 


\section{METODOLOGIA}

Trata-se de uma visão pericial, através de análise espacial, com a distribuição geográfica das perícias realizadas, onde foi utilizado o método de georreferenciamento de dados, com o objetivo de mapear frequência de ocorrências periciais, realizadas pelo Instituto de Criminalística no período de 2011 a 2018, indicando a localização das ocorrências, assim como apontando as origens das manifestações patológicas.

\subsection{SIG aplicado na análise espacial de ocorrências de manifestações patológicas de 2011 a} 2018

Com o fito de atingir o objetivo proposto na metodologia, identificaram-se os dados obtidos em planilhas Excel de todas as ocorrências periciais para posterior análise, do Instituto de Criminalística do Pará de 2011 a 2018, em seguida foram definidas as variáveis:

- Danos não estruturais são danos caracterizados por manifestações patológicas, os quais não atingem o sistema estrutural da edificação;

- Danos estruturais são danos caracterizados por manifestações patológicas constatadas nas edificações, que dão como consequência a corrosão nas ferragens, recalque nas fundações, entre outros, comprometendo os elementos estruturais de uma edificação;

- Risco de desabamento e desabamento é quando ocorre o colapso total ou parcial com desabamento da edificação ou quando as manifestações patológicas conduzem na interdição de local e desocupação do local, ou seja, quando às manifestações patológicas vierem a comprometer à estabilidade das edificações de modo geral.

Foram registradas 2879 ocorrências e dessa totalidade, 2630 ocorreram com danos não estruturais, 192 com estrutural e 57 com o risco de desabamento. E dessa forma, percebe-se uma representação de $91 \%$ de ocorrências de manifestações patológicas com danos não estruturais, conforme demonstrado na Tabela 1 e Figura 5.

Tabela 1. Quantidade de Perícias com ocorrências de problemas patológicos realizadas entre os anos de 2011 a 2018.

\begin{tabular}{|c|c|c|c|c|c|c|c|c|c|c|}
\hline \multirow{2}{*}{ FASE DE ORIGEM } & \multicolumn{8}{|c|}{ ANOS } & \multirow{2}{*}{ TOTAL } & \multirow{2}{*}{$\%$} \\
\hline & 2011 & 2012 & 2013 & 2014 & 2015 & 2016 & 2017 & 2018 & & \\
\hline Danos Não Estruturais & 388 & 358 & 404 & 365 & 281 & 316 & 264 & 254 & 2630 & 91 \\
\hline Danos Estruturais & 25 & 46 & 25 & 34 & 19 & 08 & 26 & 09 & 192 & 7 \\
\hline Risco/Desabamento & 09 & 07 & 21 & 10 & 06 & 00 & 03 & 01 & 57 & 2 \\
\hline TOTAL/ANO & 422 & 411 & 450 & 409 & 306 & 324 & 293 & 264 & 2879 & 100 \\
\hline
\end{tabular}




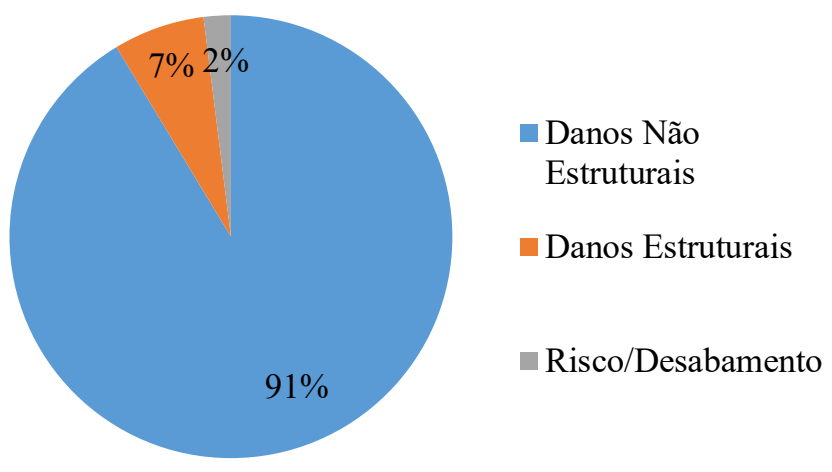

Figura 5. Distribuição da quantidade de perícias com ocorrências de problemas patológicos de 2011 a 2018.

Após esse levantamento de dados, foram filtradas 514 ocorrências, as quais atendem ao objetivo de análise das manifestações patológicas. Tratam-se de perícias realizadas em edificações residenciais, comerciais, públicas, industriais, imóveis tombados por órgãos de preservação do patrimônio histórico e arquitetônico, e obras de arte especiais. Foram apuradas as origens das manifestações patológicas, envolvendo perícias de cunho criminal e cível, identificados cinco tipos de origens das manifestações patológicas, localizadas no projeto, execução, materiais, utilização, e falta de manutenção.

Após o levantamento dos dados, obteve-se como resultado a Tabela 2, observando-se que a Execução e a falta de Manutenção se destacaram como as fases da construção com maior incidência de origem dos problemas patológicos, Figura 6.

Tabela 2. Origens das manifestações patológicas constatadas no período de 2011 a 2018

\begin{tabular}{|c|c|c|c|c|c|c|c|c|c|c|}
\hline \multirow{2}{*}{ FASE DE ORIGEM } & \multicolumn{8}{|c|}{ ANOS } & \multirow{2}{*}{ TOTAL } & \multirow{2}{*}{$\%$} \\
\hline & 2011 & 2012 & 2013 & 2014 & 2015 & 2016 & 2017 & 2018 & & \\
\hline PROJETO & 05 & 09 & 07 & 14 & 20 & 01 & 23 & 04 & 83 & 16 \\
\hline EXECUÇÃO & 25 & 39 & 48 & 35 & 22 & 28 & 27 & 25 & 249 & 48 \\
\hline MATERIAL & 01 & 03 & 02 & 04 & 10 & 01 & 03 & 02 & 26 & 5 \\
\hline UTILIZAÇÃO & 01 & 02 & 01 & 01 & 00 & 04 & 00 & 01 & 10 & 2 \\
\hline MANUTENÇÃO & 18 & 15 & 14 & 13 & 26 & 20 & 24 & 16 & 146 & 29 \\
\hline TOTAL/ANO & 50 & 68 & 72 & 67 & 78 & 54 & 77 & 48 & 514 & 100 \\
\hline
\end{tabular}




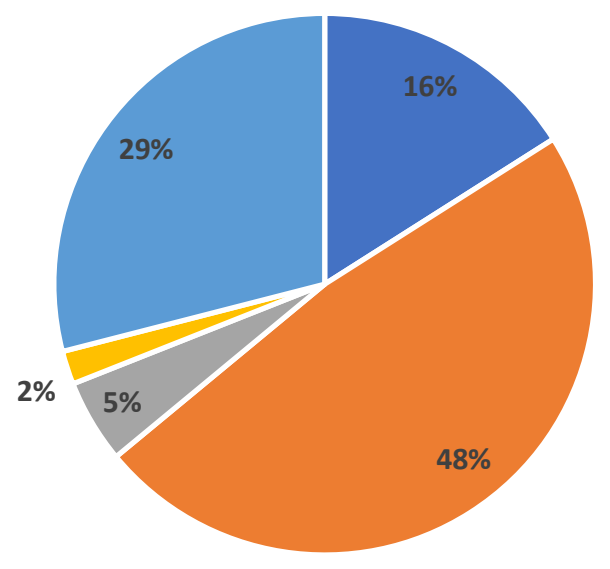

- PROJETO

- EXECUÇÃo

- MATERIAL

- UTILIZAÇÃO

- MANUTENÇÃO

Figura 6. Distribuição de total de ocorrências e origens das manifestações patológicas no período de 2011 a 2018.

\subsubsection{Técnica da análise espacial de ocorrências}

A base cartográfica empregada corresponde aos arquivos vetoriais, no formato shapefile, disponibilizadas pelo Instituto Brasileiro de Geografia e Estatística (IBGE). Os dados das ocorrências das manifestações patológicas foram georreferenciados através do software de visualização de dados Qgis e Excel.

Existem três técnicas de análise espacial através dos mapas, denominadas Mapas de pontos; Mapas de superfícies; Mapas de densidades. Para análise inicial de pontos que representariam as ocorrências foi utilizado a técnica de análise de mapas de pontos, quando, segundo Longley et al. (2013) dentre a natureza dos dados geográficos, um ponto não possui extensão, largura ou profundidade, portanto se diz ter dimensão 0 . Também é considerado como um objeto geométrico para representar ocorrências em uma localização absoluta, que pode ser usado para indicar ocorrências e representar seus padrões espaciais em mapas de pontos. 
O mapa de ponto é útil, principalmente se o número de pontos for relativamente pequeno para que seja possível apreciá-los de forma individual no mapa. Na presente pesquisa adotou-se uma amostragem de 28 municípios do estado do Pará representados pela superfície administrativa dos mesmos. (Figura 7).

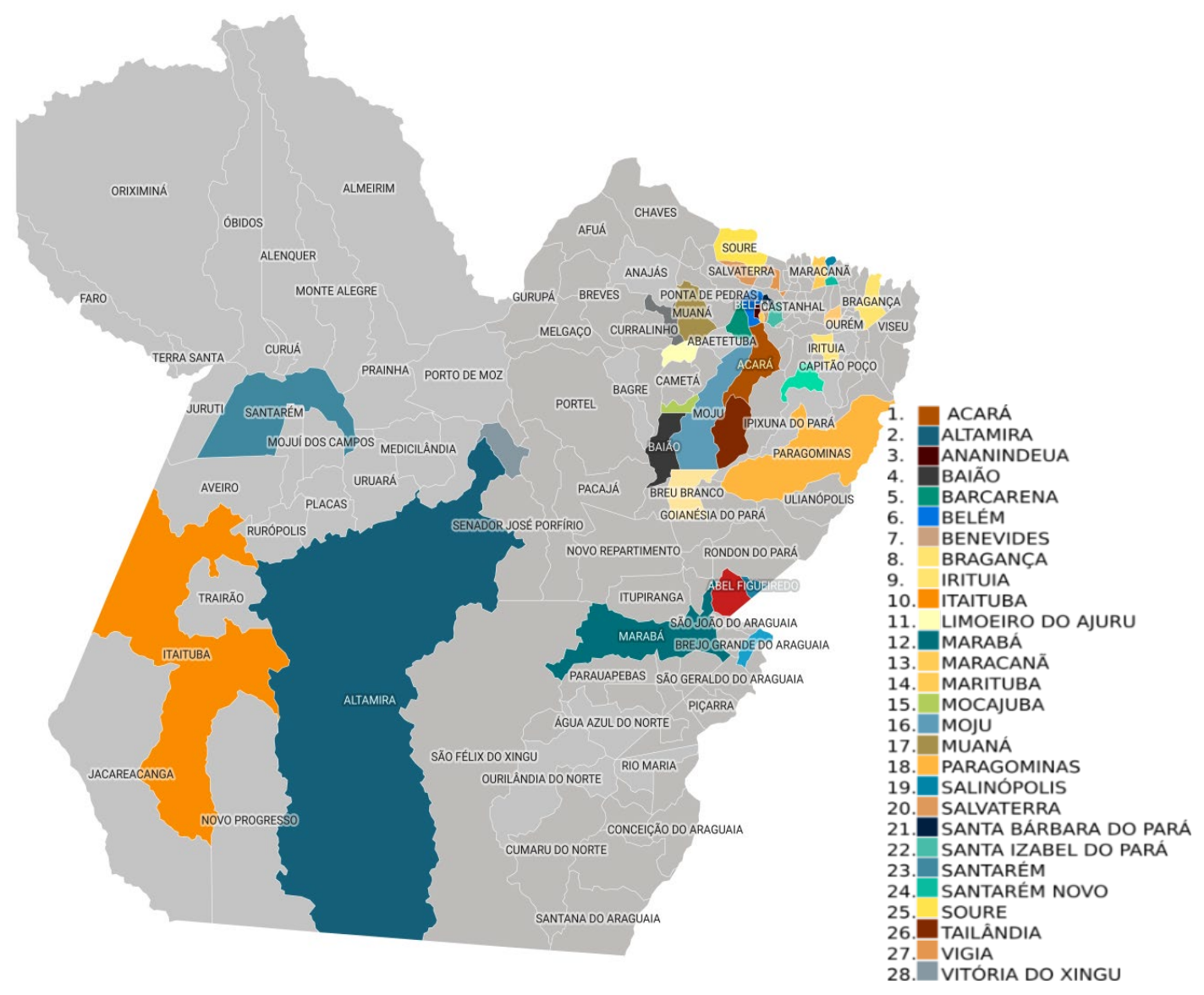

Figura 7. Amostragem dos municípios analisados do Pará.

\section{ANÁLISE DOS RESULTADOS COM USO DE SISTEMA DE INFORMAÇÕES GEORREFERENCIADAS}

No universo de quase três mil perícias criminais e cíveis, foram filtradas 514 ocorrências, as quais contemplam ao objetivo desta pesquisa, resultado das análises das origens das manifestações patológicas, referente ao total de danos constatados, percebeu-se que a Execução (48\%) e a falta de Manutenção (28\%) representam as fases da vida útil das construções, com a maior incidência de origem das falhas de construção no estado do Pará. Para melhor compreensão e melhor visualização das análises das origens das manifestações patológicas, referente ao total de danos constatados, na Figura 10 é mostrada, através do gráfico de linhas, a incidência das manifestações patológicas, durante o período de 2011 a 2018, em que são apontadas, de forma conjunta, as origens de maior número de ocorrências (execução e manutenção), nas fases em que a edificação sofreu determinado dano. 


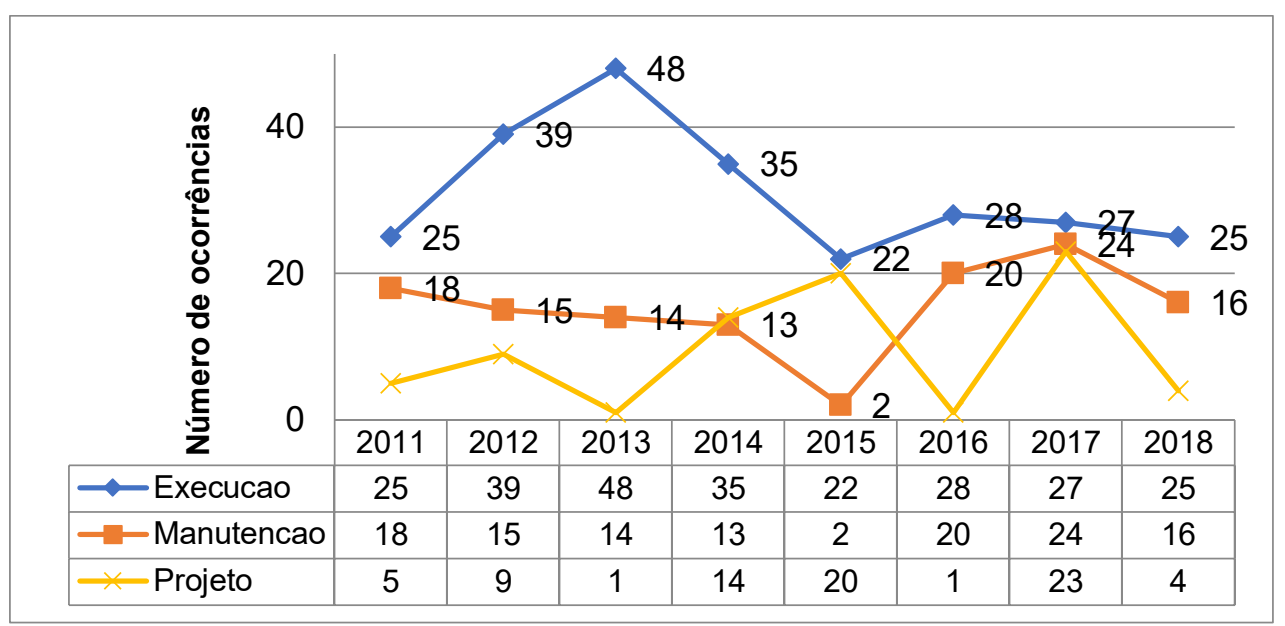

Figura 8. Distribuição das três origens, com maior número de ocorrências por ano.

As Figuras 8a, 8b e 8c mostram as repartições municipais das ocorrências durante o período de análise, extraídas do mapa (Figura 7), demonstrada no item 3. 3. 1 (Técnicas de Análise Espacial de Ocorrências), onde são apontados os municípios e as respectivas ocorrências, indicando o dano estrutural, em que foi identificada a origem dos problemas patológicos.

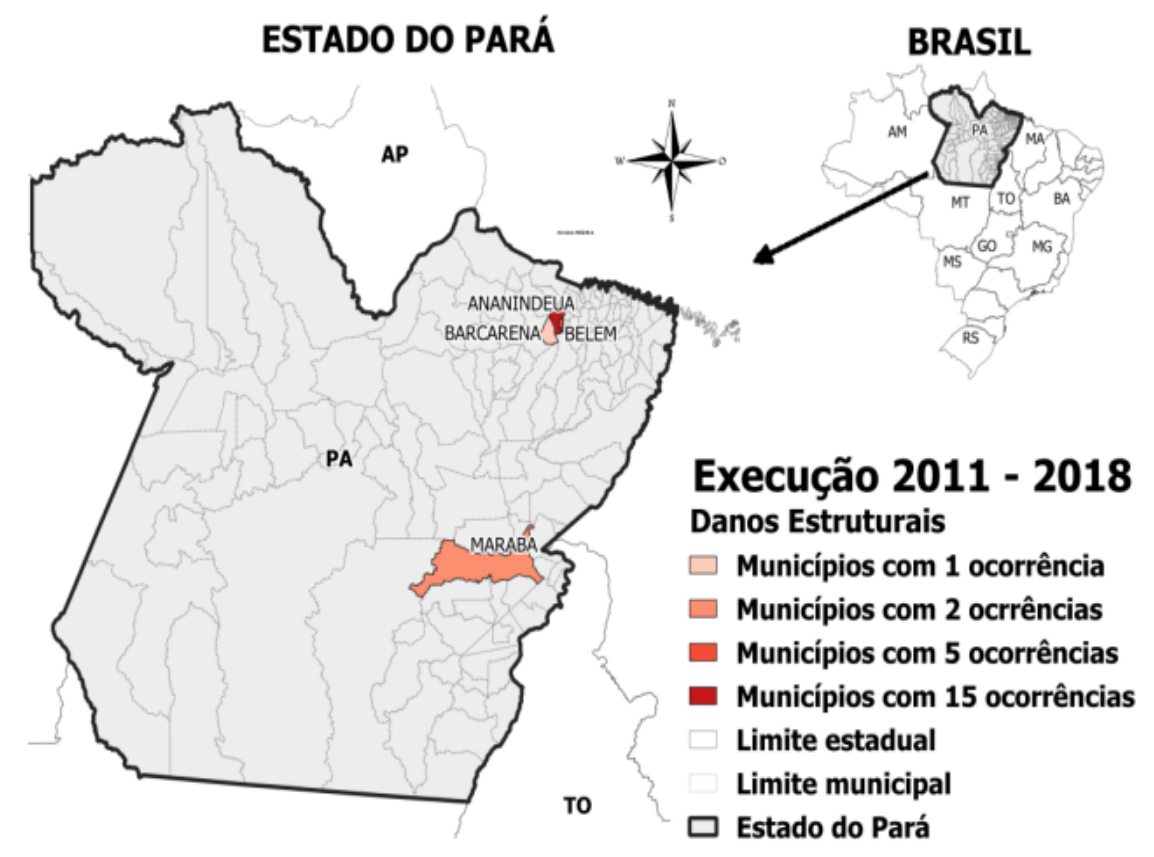

Figura 9. (a) Origem das manifestações patológicas na etapa de execução, período de 2011 a 2018 - Estrutural (Americano, Ananindeua, Barcarena, Belém, Marabá). 


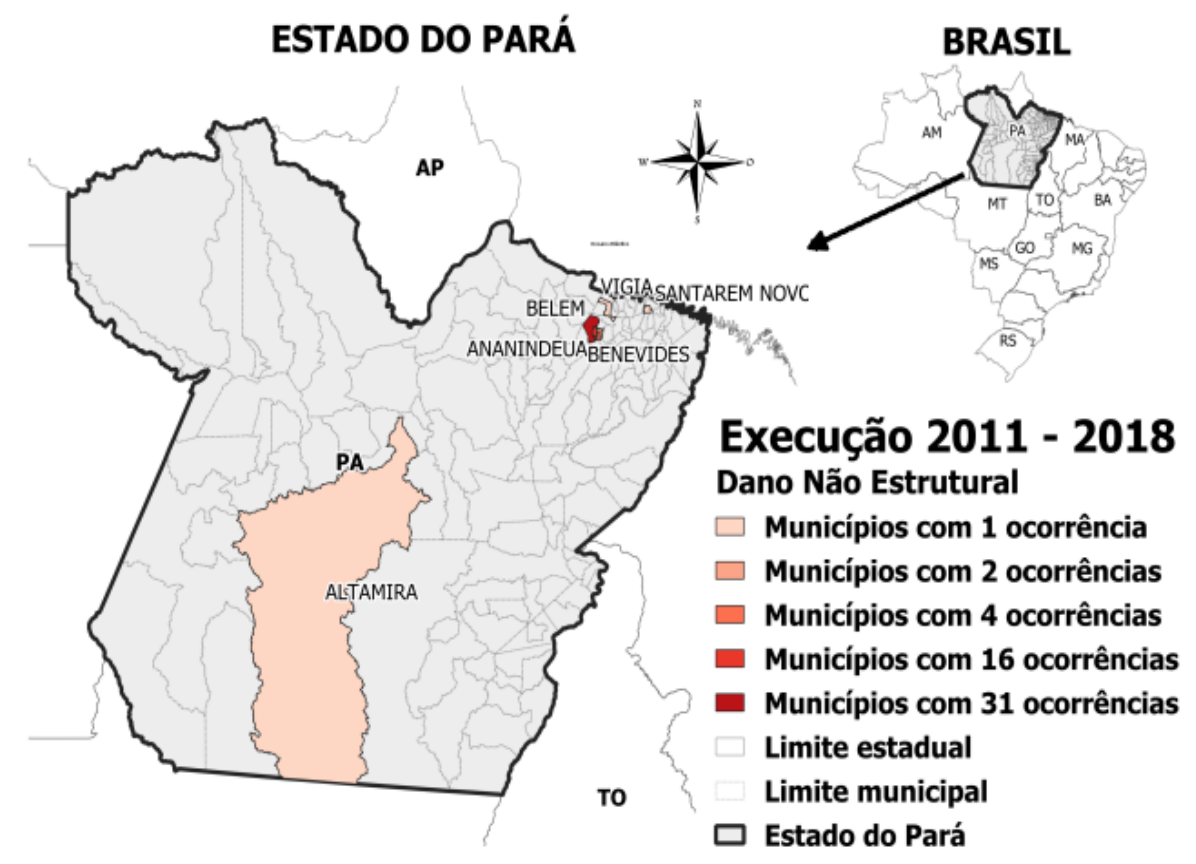

Figura 9. (b) Origem das manifestações patológicas na etapa de execução, período de 2011 a 2018 - Não Estrutural (Altamira, Ananindeua, Belém, Benevides, Marituba, Santarém Novo e Vigia).

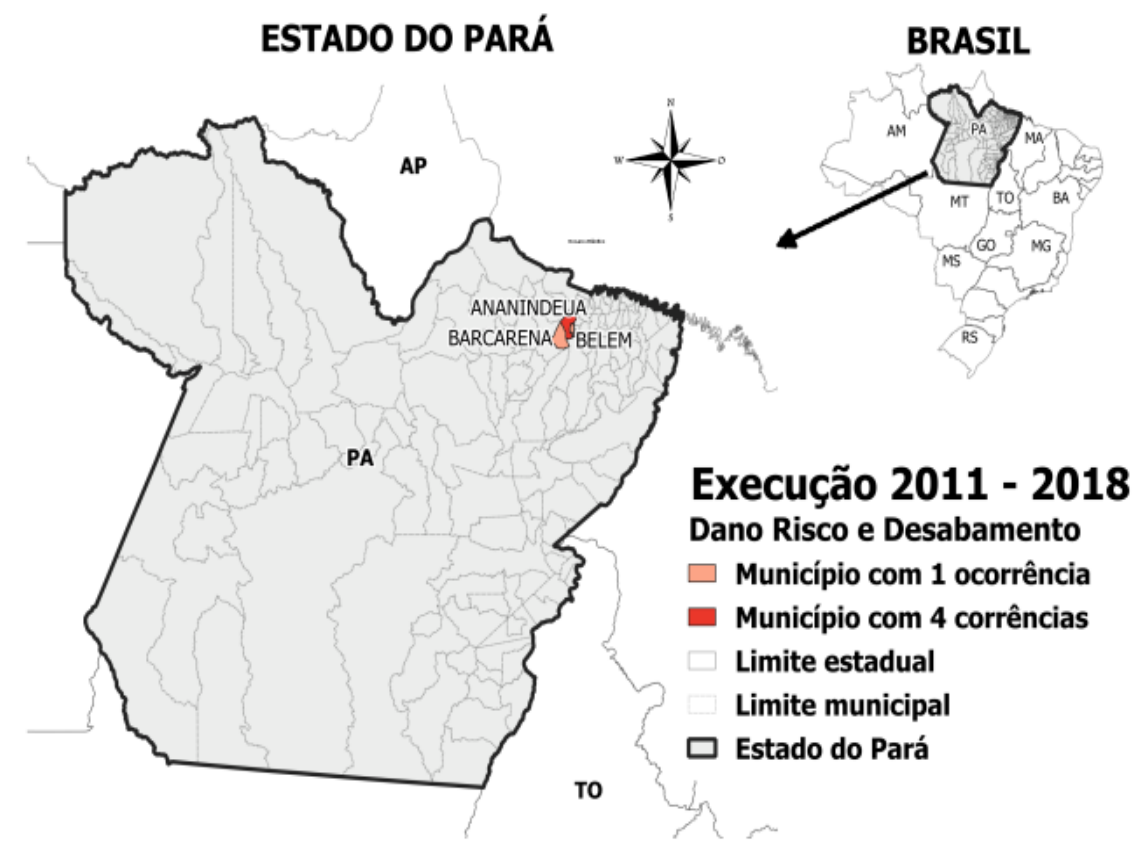

Figura 9. (c)Origem das manifestações patológicas na etapa de EXECUÇÃO, período de 2011 a 2018 - Risco e Desabamento (Barcarena, Belém, Ananindeua).

Após a utilização dos critérios de amostragem, considerando a espacialização da ocorrência, número de ocorrência por município e especificidade da ocorrência, ocorreu um filtro na 
quantidade de 514 ocorrências, e com isso é demonstrado na Figura 10, que a capital Belém destacou-se em número de frequências de ocorrências, no intervalo de 147 a 195 de ocorrências amostrais entre o período de 2011 a 2018, seguido do munícipio de Ananindeua e Marituba, ou seja, as áreas urbanas que mais solicitaram vistoria técnica.

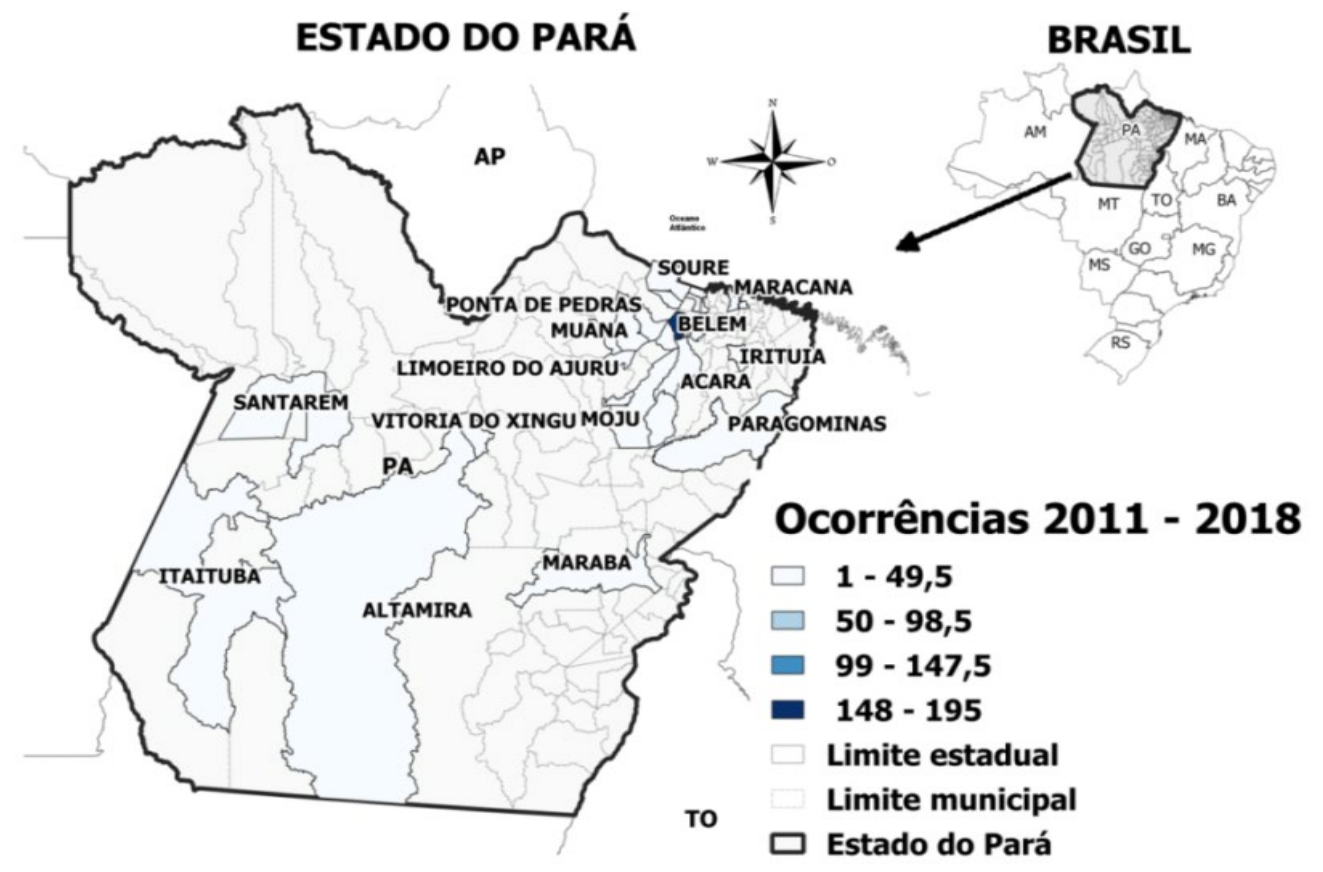

Figura 10. Mapa de destaque das ocorrências.

\section{CONCLUSÕES}

Nesta pesquisa apresentou-se com alguns exemplos a problemática das manifestações patológicas que vêm ocorrendo no Estado do Pará, a partir da análise de 514 ocorrências registradas no sistema de perícias de cunho criminal e cível, encontrando-se grande incidência devida a falhas de execução. Na análise desenvolvida dentro do período de 2011 a 2018, resultando em uma amostragem de 514 casos periciais, em que se utilizou o sistema de informações georreferenciadas, pôde-se observar a quantidade de ocorrências patológicas, no que diz respeito aos danos e demonstrou a origem das manifestações patológicas, através de gráficos e mapas, destacando a fase de execução como a maior origem dos danos constatados, correspondendo ao maior índice de ocorrências no período aludido, o que mostra a importância de programas de atualização e treinamento de mão de obra especializada no Estado.

Na sequência, após outro filtro, dentro de uma distribuição espacial das ocorrências, considerandose os critérios de espacialização da ocorrência, número de ocorrência por município e especificidade da ocorrência, percebeu-se que os centros urbanos como Belém, Ananindeua e Marituba apresentaram maior frequência de ocorrências, e observou-se que a capital Belém se destacou em número de frequências de ocorrências, no intervalo de 148 a 195 ocorrências amostrais no período de pesquisa. Diante dos resultados obtidos nessa pesquisa, observa-se que as manifestações patológicas constatadas são decorrentes da falta de um maior compromisso com a qualidade por parte dos construtores, dos responsáveis pela manutenção e por parte dos projetistas, nessa ordem. Neste sentido, cabe ressaltar que a qualidade da execução da edificação é prejudicada 
pelo pensamento da busca desenfreada da entrega do produto pronto, para ser comercializado, e a edificação após entregue é "abandonada", quando acreditam que a mesma não precisa de uma manutenção periódica, e por fim, muitas vezes no início de todo esse processo, na fase dos projetos específicos, em muitos casos, ocorre a não conformidade com as recomendações previstas nas normas técnicas, destacando-se no que concerne à capacidade resistente, ao desempenho em serviço e à durabilidade da estrutura.

\section{AGRADECIMENTOS}

Ao Centro de Perícias Científicas "Renato Chaves" por disponibilizar os laudos de perícia para consulta, por sua contribuição com informações e atenção para a pesquisa.

\section{REFERÊNCIAS}

ASSOCIAÇÃO BRASILEIRA DE NORMAS TÉCNICAS - ABNT. NBR 6118: Projeto de Estruturas de Concreto - Procedimento. Rio de Janeiro, 2014. CUNHA, A. J. P.; LIMA, N. A.; SOUZA V. C. M. Acidentes Estruturais na Construção Civil, Vol. 1, Editora PINI. 1996.

CENTRO DE PERÍCIAS CIENTÍFICAS RENATO CHAVES. Instituto de Criminalística. Laudo de Exame n⿳ 103/2008, Livro 1216, F. 204 a 220. Perícia Técnica em Estrutura. Impresso. Marabá, 2008. 2011.

Laudo de Exame $\mathbf{n}^{\mathbf{0}}$ 124/2011, Livro 010/ENG. Perícia Técnica em Estrutura. Belém, HELENE, P. R. L.; MEDEIROS, M. H. F.; ANDRADE, J. J. O. Durabilidade e Vida Útil das Estruturas de Concreto. IBRACON. 2011.

LONGLEY, P. A.; GOODCHILD, M. F.; MAGUIRE, D. J.; RHIND, D. W. Sistemas e ciência da informação geográfica. 3. Ed. Porto Alegre: Bookman Editora, 2013.

MEHTA, P. K. MONTEIRO, P. J. M. Concreto: Estrutura, Propriedades, Materiais, São Paulo, Pini, 1994.

RAIOL, R. S. B.; MACIEL, R. M.; Metodología utilizada en la evaluación de accidentes estructurales. XII Congreso latinoamericano de patología de la construcción. Y xiv congreso de control de calidad en la construcción. Cartagena de Índias/Colômbia. Vol. VII, p. 9 - 16. 2013.

SOUZA, V.; RIPPER, T.; Patologia, recuperação e reforço de estruturas de concreto. Editora Pini. São Paulo, 1998.

Disponível em:

$<$ https://www.google.com/search?q=real+class+foto+antes+do+desabamento\&sxsrf=ALeKk034 aDhUQj3PRVM1um6F1mmqnNu2fQ: $1622507312117 \&$ tbm $=$ isch\&source $=$ iu $\&$ ictx $=1 \&$ fir $=J P V$ FUrX8JqFz9M\%252CUvKncuKHjDaaMM\%252C \&vet=1\&usg=AI4 kT9CSdcI2D0N_ay0FvAt4ZXnHMdwg\&sa=X\&ved=2ahUKEwiypu flvXwAhU7JbkGHT1vD $\underline{\text { z4Q9QF6BAgQEAE\#imgrc }=J P v F U r X 8 J q F z 9 M}>$. Acesso em 31/05/2021. 